Francisco Antonio de Castro Lacaz ${ }^{1}$ José Marçal Jackson Filho Danilo Fernandes Costa ${ }^{3}$

Rodolfo Andrade de Gouveia Vilela ${ }^{4}$

1 Editor convidado. Departamento de Medicina Preventiva da Escola Paulista de Medicina da Universidade Federal de São Paulo. São Paulo, SP, Brasil.

${ }^{2}$ Editor científico da RBSO. Centro Estadual do Rio de Janeiro da Fundacentro. Rio de Janeiro, RJ, Brasil.

${ }^{3}$ Editor convidado. Superintendência Regional do Trabalho de São Paulo. São Paulo, SP, Brasil.

${ }^{4}$ Editor associado da RBSO. Faculdade de Saúde Pública da Universidade de São Paulo. São Paulo, SP, Brasil.

\section{Resultado da parceria entre a RBSO e o GT Saúde \\ do Trabalhador da Abrasco}

\author{
Result from the partnership between RBSO and Abrasco's \\ worker's health technical comitee
}

No Editorial intitulado "Atendendo a um chamamento", publicado pela Revista Brasileira de Saúde Ocupacional (RBSO) em 2010 (MACHADO; LACAZ, 2010), foi anunciada a aproximação entre o Grupo de Trabalho "Saúde do Trabalhador" da Associação Brasileira de Saúde Coletiva (Abrasco) e a editoria da RBSO, após a formalização da intenção dos editores da Revista em estabelecer relações mais consistentes com o campo Saúde do Trabalhador, inserido, frise-se, na Saúde Coletiva, a partir das formulações relacionadas à determinação social do processo saúde-doença e do protagonismo do trabalho nesta determinação.

Tal posicionamento foi defendido durante oficina do GT no IX Congresso Brasileiro de Saúde Coletiva, realizado pela Abrasco em Olinda-PE, no período de 31 de outubro a 04 de novembro de 2009, para que a RBSO, pioneira no Brasil na publicação de artigos referentes às relações Trabalho e Saúde desde 1973, portanto há quarenta anos, pudesse assumir um papel relevante na divulgação dos resultados de estudos e pesquisas desenvolvidos a partir do olhar da Saúde do Trabalhador.

No Editorial "A RBSO e seu compromisso com o campo da Saúde do Trabalhador" (ALGRANTI, E. et al., 2009), foi reforçado e anunciado que a RBSO se propunha a "[...] consolidar seus objetivos e cumprir a missão de 'publicar artigos científicos relevantes para o desenvolvimento do conhecimento e para incrementar o debate teórico científico no campo da SST'” (p. 105).

Considerando o tempo de maturação de proposições como esta, cerca de três anos e meio depois, na presente edição trazemos a público o primeiro fruto concreto daquela aproximação iniciada em 2009. Trata-se do dossiê temático Atenção integral em Saúde do Trabalhador: desafios e perspectivas de uma política pública. Nele encontram-se artigos que expressam vários desenvolvimentos teórico-metodológicos e experiências no campo da Saúde do Trabalhador, explicitando avanços na área de vigilância e de promoção, apesar dos vários limites e entraves que ainda persistem para a implantação de uma efetiva Política Nacional de Saúde do Trabalhador, como aponta o artigo debate que abre este número da RBSO.

No texto de "chamada" do dossiê, não obstante os promissores avanços teóricos e conceituais que podem ser constatados ao longo dos últimos trinta anos, havíamos relacionado aspectos essenciais e os desafios para a consolidação das práticas sociais e institucionais no tocante a: 
- implantação de uma efetiva ação interinstitucional que envolva as áreas da saúde, trabalho, previdência, meio ambiente, políticas de desenvolvimento;

- estruturação e disseminação pública de informações epidemiológicas que, além de ser um direito do cidadão, poderia orientar a priorização de ações de vigilância e prevenção;

- estruturação de uma rede articulada que se apoie em corpo funcional estável e qualificado para o enfrentamento da complexidade dos conflitos e invisibilidade dos determinantes dos riscos relacionados ao trabalho;

- fortalecimento do controle social como protagonista para a intervenção nos processos nocivos de trabalho.

Neste dossiê, em vários artigos, por meio do relato de resultados de estudos acadêmicos, frutos de projetos de pesquisas, teses e dissertações, e de experiências desenvolvidas no âmbito dos serviços da rede do Sistema Único de Saúde (SUS) em parceria com a universidade ou com outras instituições que compõem o espaço de interlocução que vem sendo construído pelo campo ao longo dos últimos trinta anos, busca-se abordar alguns dos desafios e questões acima apontados. Importante ressaltar que, no ano de 1984, ocorreu a primeira reunião científica patrocinada pela Abrasco, em Campos do Jordão, na qual se deram importantes discussões na busca de um aggiornamento das questões que já assinalavam, a partir dos Serviços de Saúde, a efervescência da emergência do campo.

Assim, ao tornar público, no volume 38, número 127 da RBSO, este primeiro conjunto de artigos relativos ao dossiê temático sobre Atenção integral

\section{Referências}

ALGRANTI, E. et al. A RBSO e seu compromisso com o campo da Saúde do Trabalhador. Revista Brasileira de Saúde Ocupacional, São Paulo, v. 34, n. 120, p. 104105, jul./dez. 2009. em Saúde do Trabalhador: desafios e perspectivas de uma política pública, concretiza-se, de forma inequívoca, a parceria entre a Abrasco, através do Grupo de Trabalho em Saúde do Trabalhador, e a RBSO. Na verdade, trata-se de dar concretude à intenção explicitada no Editorial "Atendendo a um chamamento", pois, naquela oportunidade, ainda no primeiro semestre do ano de 2010, foi dito que:

\begin{abstract}
Assim, a Abrasco, através do GT de Saúde do Trabalhador, vem a público somar-se ao chamamento anunciado pelo Conselho Editorial da RBSO, visando estabelecer uma parceria promissora para ambos os lados, na perspectiva de contribuir para que o conhecimento produzido seja socializado, e que tal fato colabore para a elaboração de políticas sociais de abrangência nacional embasadas nas formulações do campo da Saúde do Trabalhador. (MACHADO; LACAZ, 2010)
\end{abstract}

Como editores do presente dossiê da RBSO, que será composto por mais um número, esperamos que ele venha a estimular o debate acerca dos passos ainda a serem dados na caminhada em direção a uma efetiva Política Nacional de Saúde do Trabalhador no Brasil, ou seja, política que se constitua em espaço que expresse a verdadeira interlocução intra e intersetorial das várias instâncias relacionadas ao campo Saúde do Trabalhador, tanto aquelas ligadas aos trabalhadores, como aquelas vinculadas aos órgãos do Aparelho de Estado e à universidade. Dessa forma, acreditamos que a política pública poderá ter ressonância junto à sociedade civil organizada e assuma um papel importante no enfrentamento das novas e velhas questões do campo nesta etapa do capitalismo brasileiro, que continua a provocar efeitos e danos inaceitáveis à saúde dos trabalhadores tanto do campo, quanto da cidade.

MACHADO, J. H. M.; LACAZ, F. A. C. Atendendo a um chamamento. Revista Brasileira de Saúde Ocupacional, São Paulo, v. 35, n. 121, p. 6, jan./jun. 2010. 